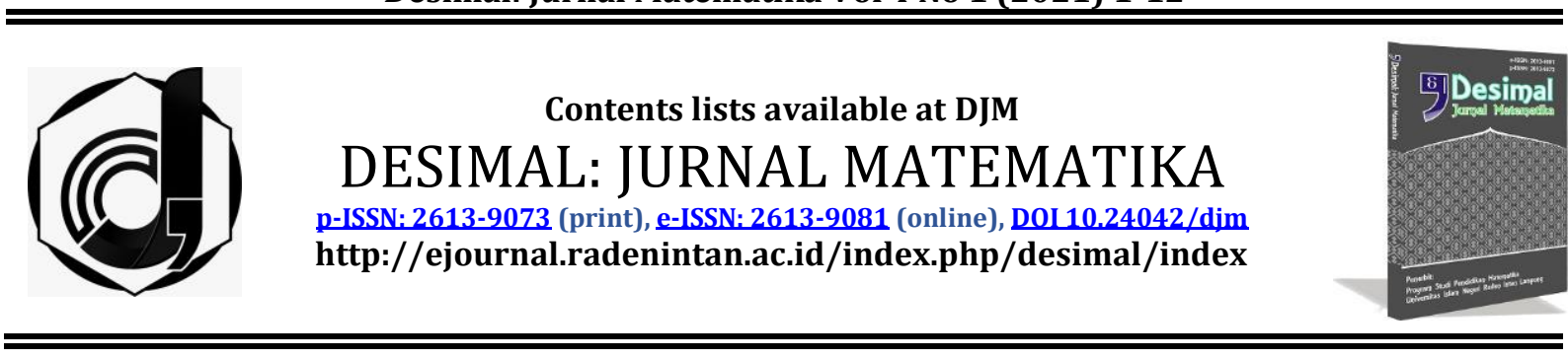

\title{
Learning geometry through surface creation from the hypocycloid curves expansion with derivative operators for ornaments
}

\author{
Hanna Arini Parhusip*, Hindriyanto Dwi Purnomo, Didit Budi Nugroho, Istiarsi Saptuti \\ Sri Kawuryan
}

Universitas Kristen Satya Wacana, Indonesia

\section{ARTICLE INFO}

\begin{tabular}{ll}
\multicolumn{2}{l}{ Article History } \\
Received & $: 31-10-2020$ \\
Revised & $: 06-11-2020$ \\
Accepted & $: 19-11-2020$ \\
Published & $: 12-01-2021$
\end{tabular}

Keywords:

Geometry Learning, Spherical

Coordinate, Hypocycloid.

* Correspondance E-mail:

hanna.parhusip@uksw.edu

Doi:

$\underline{10.24042 / \text { djm.v4i1.7385 }}$

\begin{abstract}
Geometry is one of the particular problems for students. Therefore, several methods have been developed to attract students to learn geometry. For undergraduate students, learning geometry through surface visualization is introduced. One topic is studying parametric curves called the hypocycloid curve. This paper presents the generalization of the hypocycloid curve. The curve is known in calculus and usually is not studied further. Therefore, the research's novelty is introducing the spherical coordinate to the equation to obtain new surfaces. Initially, two parameters are indicating the radius of 2 circles governing the curves in the hypocycloid equations. The generalization idea here means that the physical meaning of parameters is not considered allowing any real numbers, including negative values. Hence, many new curves are observed infinitely. After implementing the spherical coordinates to the equations and varying the parameters, various surfaces had been obtained. Additionally, the differential operator was also implemented to have several other new curves and surfaces. The obtained surfaces are useful for learning by creating ornaments. Some examples of ornaments are presented in this paper.
\end{abstract}

http://ejournal.radenintan.ac.id/index.php/desimal/index

\section{INTRODUCTION}

Geometry is one of the common problems in mathematics education (Colette, 2015). Therefore, the method to introduce geometry material to students is one of the researchers' focuses. For example, the researchers presented the material to the eighth-grade students using puppets with geometric shapes (Yilmazer \& Keklikci, 2015) or using visualization to illustrate functions (Makonye, 2014). Likewise, another learning geometry approach is materializing the topics (Serin, 2018; Wierzchon \& Klopotek, 2018). Various efforts to learn geometry show that visualization is the standard method (Baiduri et al., 2020; Bråting \& Pejlare, 2008; Claudia et al., 2015; Presmeg, 2006). Visualization technique is necessary where computers have become standard tools these days. In higher education, some software, such as Computer-Aided Design (CAD), is used to visualize geometry in a 
Desimal, 4 (1), 2021 - 2

Hanna Arini Parhusip, Hindriyanto Dwi Purnomo, Didit Budi Nugroho, Istiarsi Saptuti Sri Kawuryan

freer form complete with the mathematical operation, for example, orthogonalization (Kwanghee \& Takis, 2014; Theodore, 2016). Therefore, this research focused on geometric visualization, especially in forming curve extension surfaces with spherical coordinate transformations. This research's novelty was the curve equations (the hypocycloid) that can be extended to a surface. To increase the variation of the surface, the surfaces' differential operator equations are also shown. The hypocycloid curve equation is a parametric equation that states the curve resulting from the intersection of a circle around a larger circle. By applying a spherical coordinate transformation, an expansion produces new forms that have never been found in other literature.

\section{The Spherical Coordinate Surfaces Formation}

Cylindrical and spherical coordinates are generally introduced to students in calculus courses at the undergraduate level. These coordinate systems are introduced classically by providing an example of how a Cartesian coordinate is expressed in cylindrical or spherical coordinates, and vice versa. In such material, it is unknown how the coordinate systems construct a surface from existing parametric surfaces other than the spherical surface formed from the parametric equation for circles. Likewise, it is unknown how to modify a surface to become a new surface using other mathematical operators, such as the differential or derivative. If it is a derivative function, a surface can be obtained from the derivative of the surface or the curve's derivative extended by spherical coordinates. It has not been widely introduced in mathematics or calculus.

Points in space, apart from Cartesian coordinates, can also be expressed in cylindrical or spherical coordinates. The cylindrical coordinates are appropriate for the radial direction where the $\mathrm{z}$-axis is constant. On the other hand, for all directional points, the more appropriate is the spherical coordinates. This is rarely a concern in calculus lessons when the two coordinate systems are introduced apart from introducing formulas and examples of related problems. For this reason, this article showed the creativity of using the spatial coordinate system to construct surfaces. This research describes how the parametric curve equation is extended to become a surface using the spherical coordinate system.

\section{RESEARCH METHOD}

Curve and surface formation are widely studied in Computer-Aided Design (Miura \& Gobithaasan, 2014). However, the Betzier curve is not recognized in mathematics learning at the undergraduate level, where the Betzier curve has also been expanded to become a surface (Han et al., 2008). However, the Betzier and B-spline curves (Zhou et al., 2020) are not used. In this research, the hypocycloid curves were transformed by spherical coordinates.

\section{Spherical Coordinates}

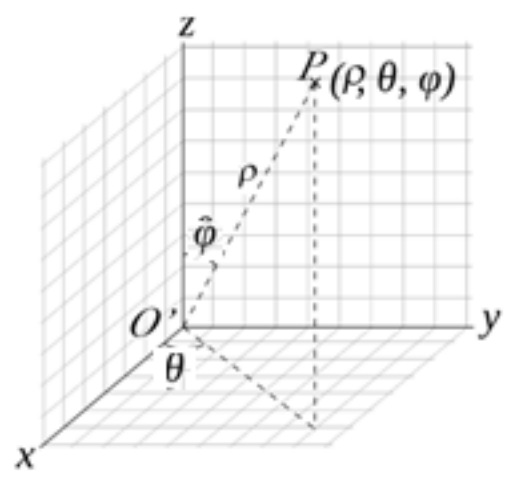

Figure 1. Spherical Coordinate System

Figure 1 displays the basic shape of the spherical coordinate system. Based on Figure 1 , any point $\mathrm{P}(x, y, z)$ written in Cartesian are transformed into cylindrical coordinates: 
Desimal, 4 (1), 2021 - 3

Hanna Arini Parhusip, Hindriyanto Dwi Purnomo, Didit Budi Nugroho, Istiarsi Saptuti Sri Kawuryan

$$
\begin{aligned}
& x=r \cos \theta ; \quad y=r \sin \theta ; z=z ; \\
& r=\sqrt{x^{2}+y^{2}} ; r \geq 0, \theta \in(0,2 \pi) .
\end{aligned}
$$

Based on Figure 1, the angle of $\theta$ can be obtained using the following relationship:

$$
\tan \theta=\frac{y}{x} \quad ; \theta=\tan ^{-1}\left(\frac{y}{x}\right) \text {. }
$$

In spherical coordinates, any point $\mathrm{P}(x, y$, $z$ ) in Cartesian coordinates can be written as follows:

$$
\begin{gathered}
x=\rho \sin \varphi \cos \theta ; y=\rho \sin \varphi \sin \theta \\
z=\rho \cos \varphi ; \rho=\sqrt{x^{2}+y^{2}+z^{2}} \\
\quad \rho \geq 0, \theta \in(0,2 \pi), \text { and } \varphi \in(0, \pi)
\end{gathered}
$$

The order of writing a point in each coordinate system needs to be focused. For Cartesian coordinates, the order is $\mathrm{P}$ $(x, y, z)$. In the cylindrical coordinate system, the order is written as $P(r, \theta, z)$, while in spherical coordinates, the order is written as $P(r, \theta, \varphi)$. In this research, the spherical coordinate equation was used to construct a surface where the plane's surface projection was known. This is shown in this paper where 2-dimensional parametric equations are mapped into 3dimensional parametric equations.

\section{The Expansion of Hypocycloid Parametric Equations}

Several parametric equations had been collected in the literature, some of which constructed parametric equations in different forms (Schlichtkrull, 2011).
The hypocycloid parametric equation is an equation where the curve is formed from the tangent's path inside the larger circle. The paths consisted of various curve shapes. If the larger circle has $a$ unit radius and the smaller circle has a $b$ unit radius $(a>b)$, then the classical hypocycloid equation has been defined in the literature. However, in this research, this equation is expanded by ignoring the physical meaning of the values $a$ and $b$. Thus, the values can be negative, can be the same, or even have irrational numbers. By ignoring the physical sign and the meaning, the expanded hypocycloid equation can be written as:

$$
\begin{aligned}
& x=(a+b) \cos \theta+b \cos \left(\frac{a+b}{b} \theta\right) ; \\
& y=(a+b) \sin \theta+b \cos \left(\frac{a+b}{b} \theta\right) ;
\end{aligned}
$$

With

$b=-p / q, 0 \leq \theta \leq 2 p \pi, 0 \leq \varphi \leq \pi$.

This equation has been used in several studies to produce curves created into innovative products such as ornaments, accessories, and batik designs (Parhusip, 2015, 2014). This article showed the variations of the parameters $a$ and $b$ using the cylindrical and spherical transformations where several innovative surfaces can be formed. Figure 2 shows an example of a curve shape where the curve parameters are $a=1, b=-p / q$ where $p=1$ and $q=4,0 \leq \theta \leq 2 p \pi, 0 \leq \varphi \leq$ $\pi$. 
Desimal, 4 (1), 2021 - 4

Hanna Arini Parhusip, Hindriyanto Dwi Purnomo, Didit Budi Nugroho, Istiarsi Saptuti Sri Kawuryan

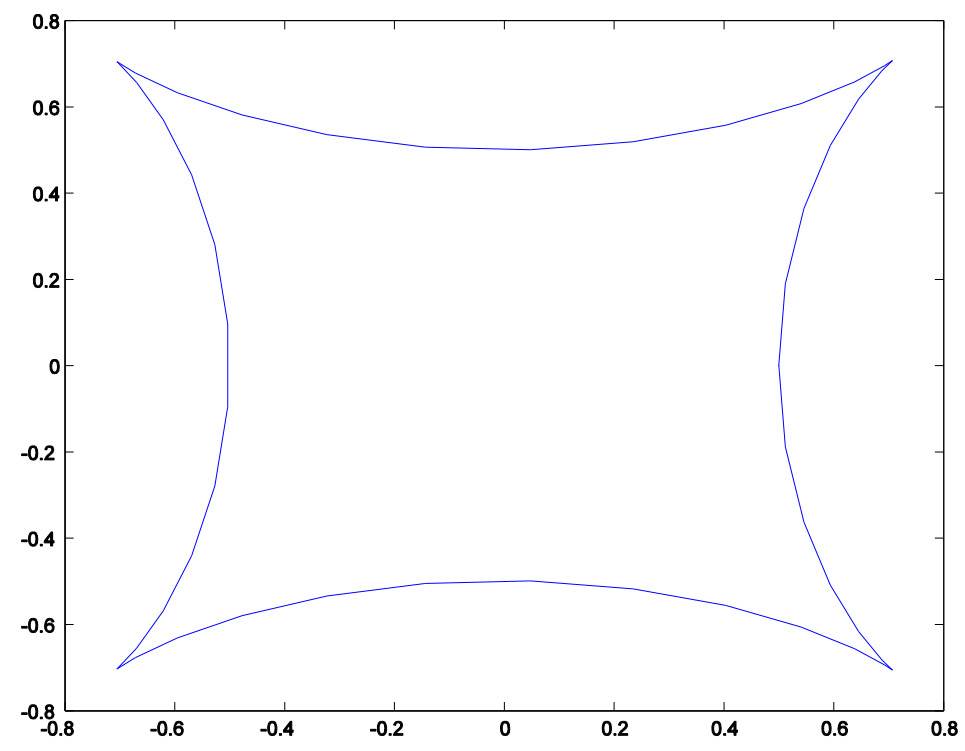

Figure 2. Curve Modification of the Hypocycloid Equation (1.a) - (1.c) with $a=1, b=$ $p / q$ where $p=1$ and $q=4,0 \leq \theta \leq 2 p \pi, 0 \leq \varphi \leq \pi$.

In calculus, the derivative of a $x_{d}=-(a+b) \sin \theta-b(a+b) \sin \left(\frac{a+b}{b} \theta\right)$ function can be formed while the derivative of a surface is not yet introduced. The derivative of equation $y_{d}=(a+b) \cos \theta+b(a+b) \cos \left(\frac{a+b}{b} \theta\right)$ (2.a) - (2.b) can be arranged into derivative of the curve from equation (1.a) - (1.b)

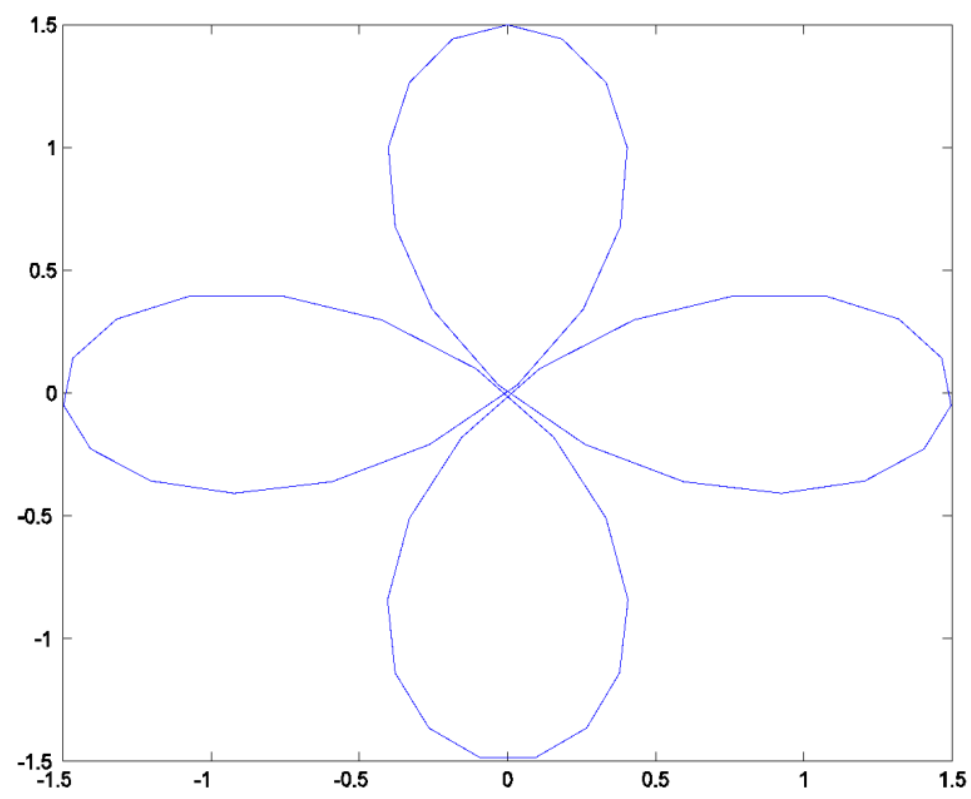

Figure 2. The Modification of Hypocycloid Curve Equation (3A) - (3b) with $a=1, b=$ $p / q$ where $p=1$ and $q=4,0 \leq \theta \leq 2 p \pi, 0 \leq \varphi \leq \pi$. 
Desimal, 4 (1), 2021 - 5

Hanna Arini Parhusip, Hindriyanto Dwi Purnomo, Didit Budi Nugroho, Istiarsi Saptuti Sri Kawuryan

Figure 2 shows that the curve intersects itself at point $(0,0)$. This equation was then extended to be a surface using spherical coordinates.

\section{Derivative Operator on a Modified Hypocycloid Curve}

It is known that a function curve for sine, cosine, and others can be derived from the function. Similarly, derivative operators can also be applied to the new curves and surfaces. Surface formation as a new educational geometric medium assisted by technology has been done by other researchers (Sinclair et al., 2017).

\section{RESULTS AND DISCUSSION}

\section{D Hypocycloid Surface}

In previous studies, the curve expansion of a parametric curve had been mapped using a complex function (Parhusip, 2014). The curve obtained was extended to the surface. Curves and surfaces can be utilized as various objects of modern geometry learning media. The objects' geometric shapes are no longer in the form of classical mathematical geometries, such as spheres, cylinders, and squares. New surface images are expressed in puzzles, batik motifs, and motifs on souvenirs (glasses and bags) (Parhusip, 2015). The formation of the curve into a surface was further developed by considering some special parametric curves. An existing classic example is when the spherical coordinates transform an inner circular parametric curve to obtain a spherical surface. An asteroid curve can be obtained with a similar idea, namely $x^{2 / 3}+y^{2 / 3}=a^{2 / 3}$, which then expanded into a surface. This equation is written in parametric form and then subjected to a spherical coordinate transformation so that the asteroid's surface is obtained in 3-dimensional form. Similarly, a 3D hypocycloid surface can be made from a modified hypocycloid equation extended into 3D. The idea of this formation was based on the analogy of arranging a circle equation to be the surface of a sphere to which the equation is extended. Similarly, the 2D parametric equation can be extended by using the spherical equation (1.c-1.d), for example the pair of points in equations (2.a) - (2.b) or (3.a) and (3.b) is a pair of $(x(\theta), y(\theta))$, Hence, the general surface formation is as follows:

$$
\begin{gathered}
x_{S}=x(\theta) \sin \phi y_{S}=y(\theta) \sin \phi \\
(4 . \mathrm{a}) \\
r=\sqrt{x_{S}^{2}+y_{S}^{2}} \\
\rho=\frac{r}{\sin \phi} ; z=\rho \cos \phi, \phi \neq 0 .
\end{gathered}
$$

Likewise, the differential operator can form a new surface where the curve or surface's derivative can be shown. By using points (2.a) - (2.b) extended to the surface with the spherical coordinates of equation (4.a) - (4.c), the 3D surface can be obtained, as shown in Figure 3. Similarly, this step can be followed by using equation (3.a) - (3.b) in equation (4.a) - (4.c). 
Desimal, 4 (1), 2021 - 6

Hanna Arini Parhusip, Hindriyanto Dwi Purnomo, Didit Budi Nugroho, Istiarsi Saptuti Sri Kawuryan

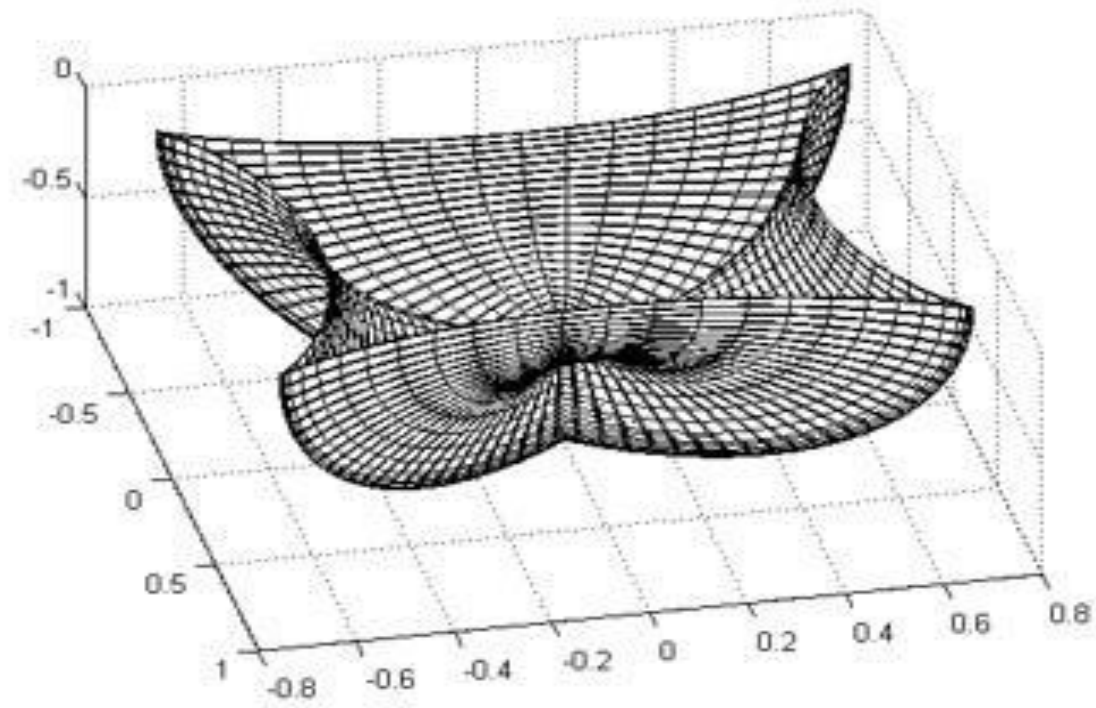

Figure 4. Surface Extension of the Hypocycloid Equation n (2.a) - (2.c) where $a=1, b=$ $-p / q$ where $p=1$ and $q=4,0 \leq \theta \leq 2 p \pi, 0 \leq \varphi \leq \pi$.

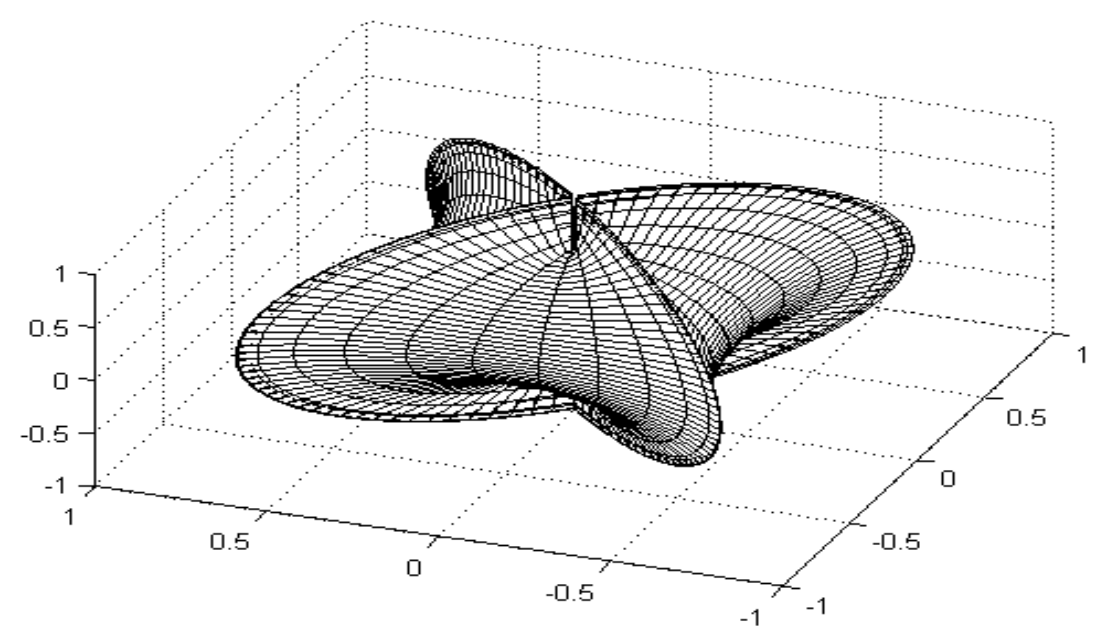

Figure 5. The Hypocycloid Modified Surface of (2.a) - (2B) with $a=1, b=p / q$ where $p=$ 1 and $q=4,0 \leq \theta \leq 2 p \pi, 0 \leq \varphi \leq \pi$.

\section{Hypocycloid Derivative Surface}

The derivative surface can be obtained by preparing a derivative which contains a parameter:

$0 .{ }^{\theta, \phi}$. The derivative can be arranged as follows:

(i) The derivative of $\phi$

$$
\begin{aligned}
& \frac{\partial x_{d, S}}{\partial \phi}=x_{d}(\theta) \cos \phi \\
& \frac{\partial y_{d, S}}{\partial \phi}=y_{d}(\theta) \cos \phi
\end{aligned}
$$

$$
\frac{\partial z}{\partial \phi}=-\rho \sin \phi
$$

(ii) The derivative of $\theta$

New Surface can also be obtained through the derivative of equations (4.a) - (4.b) by considering the $\theta$ :

$$
\begin{aligned}
& \frac{\partial x_{d, S}}{\partial \theta}=\frac{\partial x_{d}(\theta)}{\partial \theta} \sin \phi ; \\
& \frac{\partial y_{d, S}}{\partial \theta}=\frac{\partial y_{d}(\theta)}{\partial \theta} \sin \phi ;
\end{aligned}
$$




\section{Desimal, 4 (1), 2021 - 7}

Hanna Arini Parhusip, Hindriyanto Dwi Purnomo, Didit Budi Nugroho, Istiarsi Saptuti Sri Kawuryan
$r=\sqrt{\left(\frac{\partial x_{S}}{\partial \theta}\right)^{2}+\left(\frac{\partial y_{S}}{\partial \theta}\right)^{2}} ;$
$\rho=\frac{r}{\sin \phi} ; z=\rho \cos \phi \phi \neq 0$, , (6.d)
Note that ${ }^{x_{S}}$ and ${ }^{y_{S}}$ were the functions of $\theta$. Therefore, $\mathrm{z}$ had the same formula, and some innovations can be made using the same $\mathrm{z}$ value. The example of equation (6.a) - (6.d) is illustrated in Figure 6.

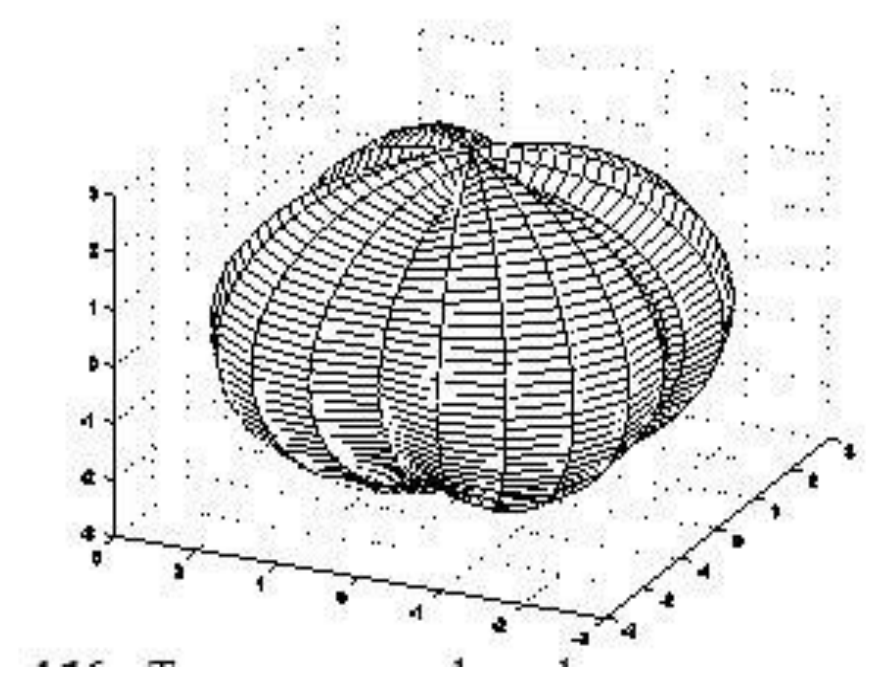

Figure 6. The Illustration of a Surface with Equation (6.a) - (6.d) with $a=1, b=-p$ / $q$ where $p=1$ and $q=4,0 \leq \theta \leq 2 p \pi, 0 \leq \varphi \leq \pi$.

\section{Further Surface Innovation}

Having obtained surface formulations, a hybrid surface can also be arranged with ease. By symbolizing $(\bullet, \bullet, \bullet)$ into the surface equation, several surface innovations can be formed, namely:
(i) $\left(\frac{\partial x_{d, S}}{\partial \theta}, \frac{\partial y_{d, S}}{\partial \theta}, \frac{d z}{d \emptyset}\right)$
(ii) $\left(\frac{\partial x_{S}}{\partial \emptyset}, \frac{\partial y_{d, S}}{\partial \theta}, z\right)$

in transparent color. 
Desimal, 4 (1), 2021 - 8

Hanna Arini Parhusip, Hindriyanto Dwi Purnomo, Didit Budi Nugroho, Istiarsi Saptuti Sri Kawuryan

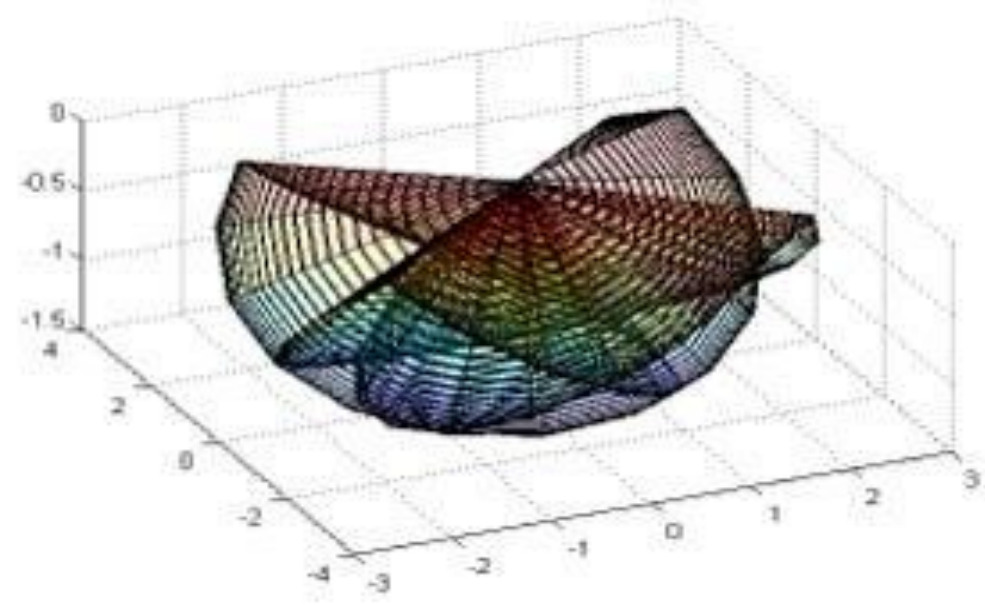

Figure 7. The Illustration of

with $a=1, b=-p / q$ where $p=1$ and $q=4,0 \leq \theta \leq 2 p \pi, 0 \leq \varphi \leq \pi$.

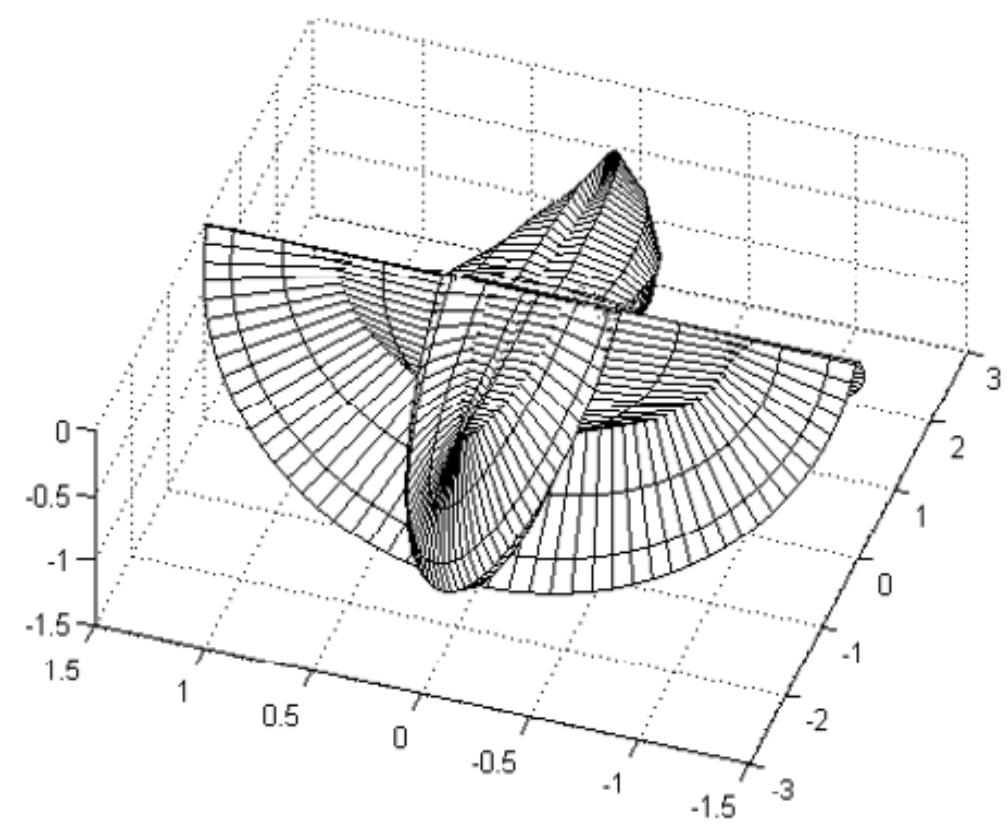

Figure 8. The Illustration of $\left(\frac{\partial x_{d, S}}{\partial \theta}, \frac{\partial y_{d, S}}{\partial \theta}, \frac{d z}{d \emptyset}\right)$ 
Desimal, 4 (1), 2021 - 9

Hanna Arini Parhusip, Hindriyanto Dwi Purnomo, Didit Budi Nugroho, Istiarsi Saptuti Sri Kawuryan

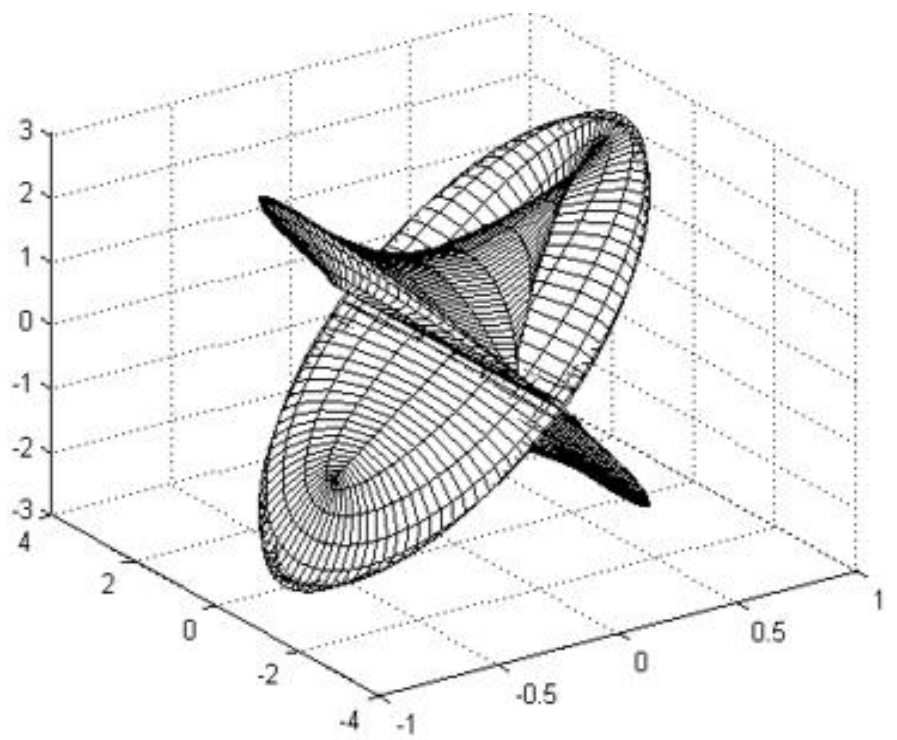

Figure 9. The Illustration of $\left(\frac{\partial x_{S}}{\partial \emptyset}, \frac{\partial y_{S}}{\partial \theta}, z\right)$

\section{Surface Utilization for Ornament}

The previous section shows the surface formed from an extended hypocycloid curve with various parameters and differential operators. The following shows how the surface becomes several ornaments and even into a specific useful form design. Figure 10 shows one of the results of the second derivative surface of the hypocycloid surface. This surface becomes the hair extension design, as shown in Figure 11.
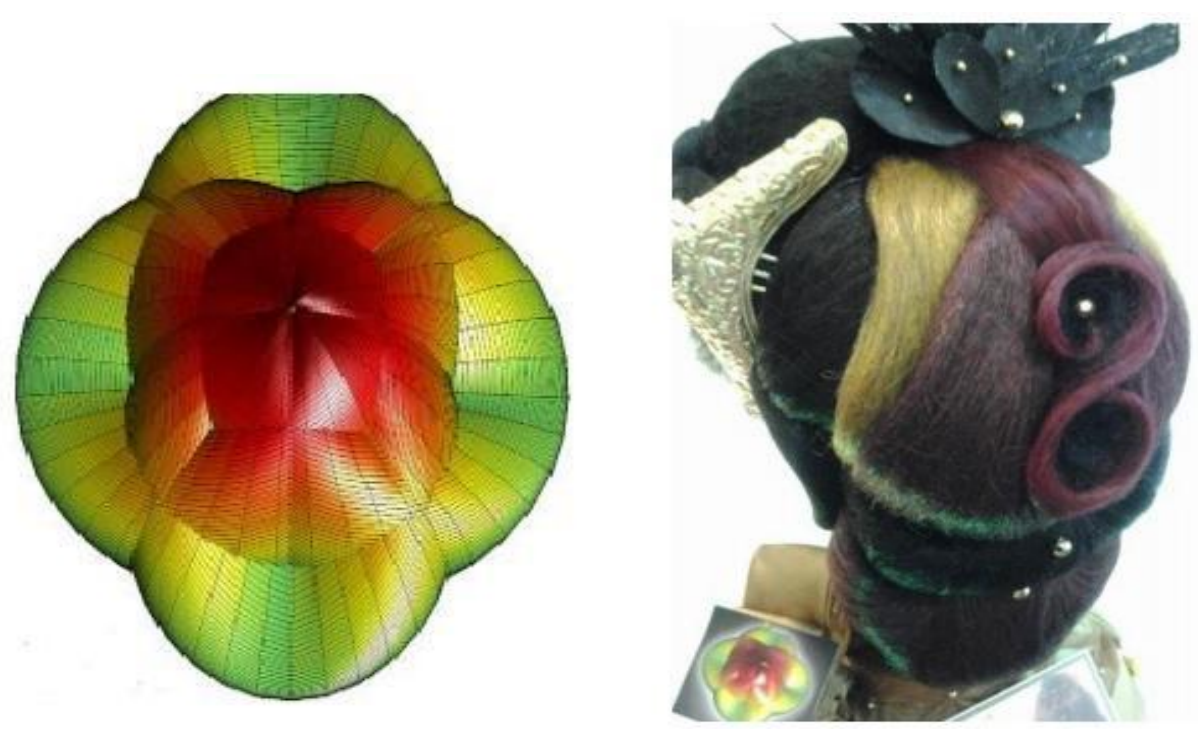

Figure 10. The Illustration of the $2^{\text {nd }}$ derivative of the surface (top) and the hair extension ornament (bottom) using equation (6.a) - (6.d) with $a=1, b=p / q$ where $p=1$ and $q=4,0 \leq \theta \leq 2 p \pi, 0 \leq \varphi \leq \pi$. 
Desimal, 4 (1), 2021 - 10

Hanna Arini Parhusip, Hindriyanto Dwi Purnomo, Didit Budi Nugroho, Istiarsi Saptuti Sri Kawuryan

Likewise, other surfaces-shaped ornaments can be obtained using other parameters.
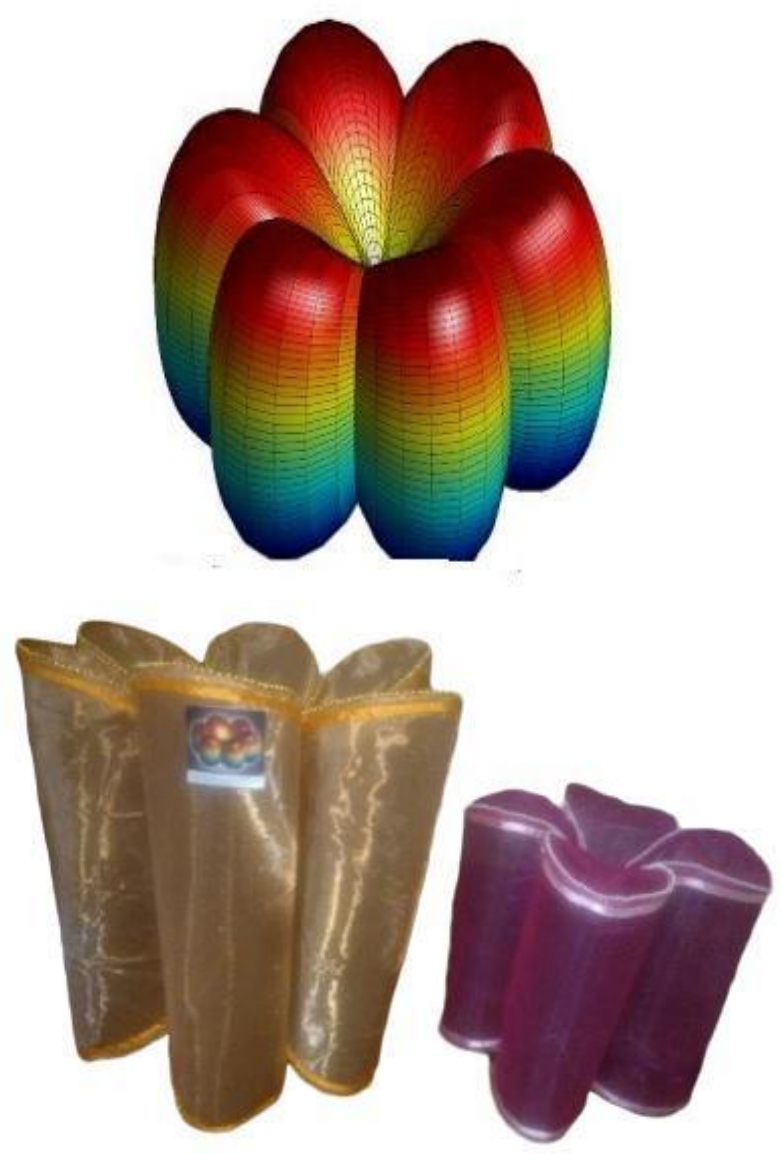

Figure 11. The Illustration of the $2^{\text {nd }}$ derivative of the surface (top) and hair extension ornaments (bottom) using equation (6.a) - (6.d) with $a=1$ where $p=1$ and $q=6,0 \leq$ $\theta \leq 2 p \pi, 0 \leq \varphi \leq \pi$.

Other creations had also been created but are not shown in this paper. Several other geometry learning media were made using other approaches with the same goal: to provide innovative geometry learning media (Parhusip \& Susanto, 2018).

\section{CONCLUSION AND SUGGESTION}

In this research, hypocycloid expansion curves can be transformed into surfaces through spherical coordinates. The two parameters in the original equation represent the radii of the two different circles. The two parameters were free, which means that they can also be negative; therefore, various curves had been obtained. Furthermore, the obtained curves and surfaces can be searched using derivative equations to obtain new curved forms and surfaces. This shows the benefits of the derivative operator toward the surface.

After the surface shapes had been obtained, they can be used as puzzle models for students. The students can study the derivative operators of a surface, which are usually only introduced to a function or equation. Likewise, surface shapes can be introduced as new motifs in batik designs, as done using algebraic surfaces (Parhusip, 2018).

\section{Acknowledgments}




\section{Desimal, 4 (1), 2021 - 11}

Hanna Arini Parhusip, Hindriyanto Dwi Purnomo, Didit Budi Nugroho, Istiarsi Saptuti Sri Kawuryan

This research is a result Ristekdikti in 2016/2017 and the results of PPUPIK community service activities at SWCU in $2020 / 2021$.

\section{REFERENCES}

Baiduri, Ismail, A. D., \& Sulfiyah, R. (2020). Understanding the concept of visualization phase student in geometry learning. International Journal of Scientific and Technology Research, 9(2), 2353-2359.

Bråting, K., \& Pejlare, J. (2008). Visualizations in mathematics. Erkenntnis, 68(3), 345-358. https://doi.org/10.1007/s10670008-9104-3

Claudia, O., Rodríguez Erla M, Morales Morgado, F., \& Gonçalves da Silva, C. M. (2015). Learning objects and geometric representation for teaching "definition and applications of geometric vector." Journal of Cases on Information Technology (JCIT), 17(1).

https://doi.org/10.4018/JCIT.20150 10102

Colette, L. (2015). Teaching and learning geometry. The Proceedings of the 12th International Congress on Mathematical Education. Springer, Cham., 431-436.

Han, X. A., Ma, Y. C., \& Huang, X. L. (2008). A novel generalization of Bézier curve and surface. Journal of Computational and Applied Mathematics, 217(1), 180-193.

https://doi.org/10.1016/j.cam.2007. 06.027

Kwanghee, K., \& Takis, S. (2014). Orthogonal projection of points in CAD/CAM applications: an overview. Journal of Computational Design and Engineering, Volume 1,(2), 116-127. https://doi.org/https://doi.org/10.7 315/JCDE.2014.012

Makonye, J. P. (2014). Teaching functions using a realistic mathematics education approach: a theoretical perspective. International Journal of Educational Sciences, 7(3), 653-662. https://doi.org/10.1080/09751122. 2014.11890228

Miura, K. T., \& Gobithaasan, R. U. (2014). Surfaces in computer-aided geometric design. Int. J. of Automation Technology, 8(1), 304-316. https://doi.org/10.1016/01663615(83)90060-x

Parhusip, H. . (2018). Algebraic surfaces for innovative education integrated in batik art (J. Yoga Dwi, A. Rodliyati, P. Mauludi Ariesto, S. Anna, \& K. Corina (eds.)). AIP Conference Proceedings.

Parhusip, H. . (2015). Disain ODEMA (ornament decorative mathematics) untuk populerisasi matematika. In $\mathrm{P}$. Widyaningsih, N. . Kurdhi, H. . Cahyono, R. Aggrainingsih, \& A. Doewes (Eds.), Proceeding, Seminar Nasional Matematika,Sains dan Informatika, dalam rangka Dies Natalis ke 39 UNS, FMIPA, UNS, (pp. 815). Universitas Sebelas Maret (UNS). Parhusip, H. A. (2014). Arts revealed in calculus and its extension. International Journal of Statistics and Mathematics, 1(3), 016-023.

Parhusip, H. A., \& Susanto, B. (2018). Inovasi geometri sebagai media pembelajaran matematika kreatif. Jurnal Matematika Kreatif-Inovatif, 9(1), 63-70. https://doi.org/https://doi.org/10.1 5294/kreano.v9i1.14047

Presmeg, N. (2006). Research on visualization in learning and teaching mathematics. Handbook of Research on the Psychology of Mathematics Education, November, 205-235. https://doi.org/10.1163/97890879 01127_009

Schlichtkrull, H. (2011). Curves and surfaces- lecture notes for geometry 1. In Notes.

Serin, H. (2018). Perspectives on the teaching of geometry: Teaching and learning methods. Journal of 
Desimal, 4 (1), 2021 - 12

Hanna Arini Parhusip, Hindriyanto Dwi Purnomo, Didit Budi Nugroho, Istiarsi Saptuti Sri Kawuryan

Education and Training, 5(1), 1. https://doi.org/10.5296/jet.v5i1.12 115

Sinclair, N., Bartolini Bussi, M. G., de Villiers, M., Jones, K., Kortenkamp, U., Leung, A., \& Owens, K. (2017). Geometry education, including the use of new technologies: A survey of recent research. November, 277-287. https://doi.org/10.1007/978-3-31962597-3_18

Theodore, S. (2016). Differential geometry: A first course in. In Differential Equations.

Wierzchon, S., \& Klopotek, M. (2018). Modern algorithms of cluster analysis studies in big data Vol.34 (J. Kaccprzyk (ed.)). Springer International Publishing.

Yilmazer, Z., \& Keklikci, H. (2015). The effects of teaching geometry on the academic achievement by using puppet method. Procedia - Social and Behavioral Sciences, 191, 2355-2358. https://doi.org/10.1016/j.sbspro.20 15.04 .463

Zhou, H., Cui, J., Tian, G., Zhu, Y., \& Jia, C. (2020). Modeling technology of curved surface development for puffer fish. Advances in Mechanical Engineering, 12(4), 1-10. https://doi.org/10.1177/16878140 20916025 